\title{
Revisiting perceptions and evolving culture: a community dialogue on women in polar research
}

\author{
Sandra Starkweather $\mathbb{1}^{\mathrm{a}}$, M. Seag ${ }^{\mathrm{b}}$, O. Lee ${ }^{\mathrm{c}}$ \& A. Pope ${ }^{\mathrm{d}}$ \\ aCooperative Institute for Research in Environmental Sciences, University of Colorado, Boulder, CO, USA; bScott Polar Research Institute, \\ University of Cambridge, Cambridge, UK; International Arctic Research Center, University of Alaska Fairbanks, Fairbanks, AK, USA; \\ dinternational Arctic Science Committee, Akureyri, Iceland
}

\begin{abstract}
Women have made outstanding contributions to polar research in recent decades, though full engagement may be hindered by persistent inequities, including notably the prevalence of workplace harassment. Remote field settings, such as those pervasive in polar research, have been identified as particularly susceptible to cultures of harassment. It was therefore timely at the Polar 2018 Open Science Conference in Davos, Switzerland, to convene a discussion focused on women's perspectives and experiences. A panel discussion-"From Entering the Field to Taking the Helm: Perspectives of Women in Polar Research" - took place on 20 June 2018 and featured five women undertaking work from marine biotechnology to organizational leadership, across career levels. Over 300 conference attendees joined the lunchtime panel. The panellists' perspectives on historical barriers, current challenges and future prospects revealed that while challenges persist, experiences vary greatly. Audience engagement underscored the need to sustain dialogue at polar meetings, to bring visibility to the statistics related to workplace harassment and to encourage polar science organizations to assume leadership on promoting equitable workplace culture.
\end{abstract}

\section{KEYWORDS}

Gender; equity; harassment; culture; science; Open Science Conference

\section{ABBREVIATIONS}

IASC: International Arctic Science Committee; SCAR: Scientific Committee on Antarctic Research

\section{Background}

Women's participation in polar research has grown steadily as cultural and institutional barriers to their participation have decreased (Rosner 2009; Hulbe et al. 2010; Carey et al. 2016). However, in spite of decades of progress, including women's ascension to leadership at key institutions, challenges persist. The high prestige of work associated with remote field sites, long vessel cruises and sustained studies within northern communities has often been accompanied by high barriers to female participation. Twentiethcentury policies barring women from polar field sites (Seag 2017) have left a legacy of field cultures centred around masculine norms (Rosner 2009; Glasberg 2012; Carey et al. 2016). Today, as hard barriers are falling, these norms need revisiting, and expected codes of conduct in field sites must be clearly articulated and enforced (Starkweather et al. 2017). A growing body of evidence, including the SAFE study (Clancy et al. 2014), has recently underscored the much more damaging impact of harassment directed disproportionally at women participating in fieldwork, ranging from the rare but most explicit forms of violence to subtle but more pervasive gender harassment. Polar research is not immune to these threats to safety and inclusivity (Bell \& Koenig 2017; Waldman 2018).
Recently, Nelson et al. (2017) have documented the prevalence of career exits due to negative experiences with scientific field programmes, particularly those that do not enforce codes of conduct. Other scholars have emphasized that female scientists can fail to achieve the "visibility" of male peers, even when their work is equally impactful (e.g., Oreskes 1996). The combined effects of these stressors may account for a greater portion of the so-called "leaky pipeline" effect (Goulden et al. 2011), describing the progressive loss of female talent from the science labour pool, than has been previously understood (SRT 2018).

Last month, the US National Academies of Science, Engineering, and Medicine released the results of a sweeping, multi-year study on harassment in the sciences (NASEM 2018). Their study found that between $20 \%$ and $50 \%$ of female students in US science, engineering and medicine reported having experienced harassing behaviour perpetrated by staff or faculty; more than $50 \%$ of faculty also said they had experienced harassment. LGBTQ women and women of colour were more likely than their straight, white counterparts to have been harassed, and women of colour were more likely to report feeling unsafe because of their gender. The study also recognized a problematic dearth of data. 
This dearth of data is true in the polar regions too, but the recent work of Nash et al. (2018) provides an important first look. Their survey of researchers in the Australian Antarctic Program revealed that 64\% of female participants experienced harassment, and, like the SAFE study, found that these incidents go largely unreported. Meanwhile, media reports concerning female geologists working under the US Antarctic Program (Scoles 2018) put a harrowing face on how such harassment can proceed unchecked in remote and isolated locations. Data from nonWestern countries and data on Arctic research are even scarcer. Given these facts, a fresh round of examinations of polar work cultures is called for.

The International Polar Year 2007-09 opened many doors to researchers from around the world (Krupnik et al. 2011), including women, so it was timely at the Polar 2018 Open Science Conference for a discussion focused on women's experiences in polar research. The panel discussion-"From Entering the Field to Taking the Helm: Perspectives of Women in Polar Research"-took place on 20 June and featured five women in disciplines ranging from marine biotechnology to organizational leadership to history of science. While the "Taking the Helm" event centred on the perspectives of women, it was important to the organizers to avoid essentializing "women" and further to recognize that gender is nonbinary. Further, it was important to recognize that many intersecting identities can result in overlapping challenges that require specific attention. Panellists represented plural intersecting factors spanning career levels, research discipline, professional roles and national and ethnic identities.

\section{From the event}

The event drew more than 300 participants representing 32 countries, who engaged in a vibrant, interactive dialogue with the panellists following interview questions by independent journalist Hannah Hoag. Hoag's questions explored aspects of the panellists' experiences including: landmark achievements; challenges related to retention, mentoring and the \#metoo movement in science; and redefining leadership.

Hoag introduced the discussion by acknowledging her surprise at the relatively recent history of women's inroads to polar work and the leading achievements of some of the panellists. HongKum Lee, a former director of the Korean Polar Research Institute, was among the first women to assume the leadership of any polar institute. During her tenure as director (2007-2013), she oversaw the completion of Korea's first research icebreaker, Aaron, and the JangBogo Antarctic Research Station in Terra Nova Bay. Lee noted that her position empowered her to budget for appropriately sized field equipment for female participants-a key safety advancement. Susan Barr, IASC's first female leader, characterized her field experiences as overwhelmingly positive, even as she was blazing trails. While taking on a role that required extensive fieldwork in Svalbard did expose her to improperly sized equipment and scepticism related to her abilities to operate firearms or outboard motors, she met these hurdles with a sense of humour. Morgan Seag, a doctoral candidate in geography studying women's advancements into Antarctic research, shared that her work was inspired by senior female researchers like these "who changed my conception of what my future could look like. I had assumed that my sixties and seventies would involve hammocks and grandbabies-these powerful women [in Antarctica] showed me how narrow that idea was. I could [like them] be camping on the ice sheet, making discoveries." Seag went on to observe that the Antarctic culture for female researchers is still mixed in spite of these pioneers' contributions. In response to an audience question about sexualization of women in the field, she noted the enduring prevalence of comparing and "rating" female field team members on their attractiveness across field sites on the continent.

Challenges are by no means limited to field sites. Arctic researcher Colleen Strawhacker, an archaeologist who works with Indigenous communities in both Alaska and the American South-west, recounted her own experiences with bullying during proposal preparation at the hands of senior male investigators, which caused her to note: "You can either fight for a seat at the table or build your own table. Both are exhausting." While she stood her ground against the bullying behaviour, she fears the type of retaliation that could await her through anonymous community processes like proposal or publication review. These anxieties were echoed by an audience member who had taken similar positions.

These and other challenges prompted Hoag to turn to the panellists for their ideas about how to move forward. Chandy Nath, the new executive director of SCAR, shared her view that "we need to reimagine what leadership looks like". She and others acknowledged that there can be an unconscious image in our heads when we think about polar research, i.e., the frosty beard, and that it takes deliberate efforts to broaden that view. Or as others have noted: "If you aren't being consciously inclusive, you are likely being unconsciously exclusive." All panellists agreed that early career researchers should not let perceptions about barriers stand in their way.

Audience questions honed in on and amplified those sentiments of the panellists focused on barriers and challenges. Multiple audience comments also focused on the low numbers of men present in the audience, who accounted for about $5 \%$ of the 
participants. Even if stemming from positive intentions, such as to allow women to have their own space, a lack of male participation in these conversations was viewed as particularly problematic related to the road towards creating more inclusive polar research cultures.

The event generated a strong response across social media platforms, where hundreds-both inside and outside the room-participated in the virtual conversation following the hashtag \#PolarWomen2018, eventually reaching a social media audience of more than 800000 Panellists' perspectives were augmented through the development of an Instagram effort eliciting input through a series of questions. The Instagram account has grown a steady following from zero to over 600 followers in 10 weeks. The resulting Women in Polar Science compilation, which currently numbers 50 profiles, continues to enrich our understanding of the plurality of experiences and achievements of women in polar research, and highlights the potentials and aspirations of a generation of women poised to impact the world. Reflected in these profiles are the joys of collegiality and accomplishment in positive work environments; the importance of believing in yourself, following your instincts, supporting colleagues and not letting biases stand in your way; and a clear love of polar environments and people.

\section{Moving forward}

The innovations required to address the next generation of polar research questions surpass the bounds of the physical, chemical or biological sciences alone. Future challenges will require systems thinking, inclusive collaboration and the dismantling of socially enmeshed barriers to progress. What better way to prepare a generation of scientists to meet the challenges posed by rapid ecological change, muchneeded interdisciplinary work and the paradigmatic shift towards knowledge co-production than through raising cultural awareness and equity within our own ranks?

The overwhelmingly strong presence of early career researchers at the event suggests that there will be a continued demand to sustain inclusivity dialogues; some senior researchers were dismayed that "we still need to have these conversations". These types of generational differences may reflect shifting norms, or they may reflect a subtler selection bias whereby certain types of adaptive strategies, natural to some and quite foreign to others, improve survivorship in research settings (e.g., McNutt 2017; Willenbring 2018). As Cheryl Rosa of the US Arctic Research Commission notes in her Instagram profile, "[i]t would be nice not to need any strategy" to succeed as a woman in polar research. Will the future impact of women in polar research be limited by their ability to strategize around gender barriers? Or is our community willing to evolve culturally, to dismantle those barriers and broaden our image of who contributes to scientific excellence and how?

The answer lies in part with our institutions, including international science bodies like IASC and SCAR. Cultural shifts take time and deliberate remedies. The US National Academies of Sciences, Engineering, and Medicine study recognized that solutions to harassment in the geosciences will require a "system wide change to the culture and climate". System-wide change of this type starts with dialogue, an important objective of the "Taking the Helm" event. Yet without stronger participation from male colleagues, system-wide change will not advance. IASC executive secretary Allen Pope, a coorganizer for the event, asked on Twitter: "Do we have sufficient 'buy-in' to the staggering statistics about harassment to make a change?" Each of us who has personally experienced such harassment might reflect on the value of sharing these experiences more openly to build such buy-in. Further, we need to promote the types of culture and climate surveys that reveal the experiences of researchers in our proximal settings, including those who wish to remain anonymous. Polar institutions like IASC and SCAR could play key roles in supporting surveys to establish a baseline of experiences against which we could formulate remedies and measure progress. In the meantime, it is imperative that organizations like the Forum of Arctic Research Operators and the Council of Managers of National Antarctic Programs continue to grow a role for themselves in preventing and responding to sexual harassment in polar field settings. A beneficial starting point, as raised through the social media commentary, would be to help make acceptable norms of behaviour well understood and enforced.

Indigenous participants were notably underrepresented at Polar 2018 for a variety of reasons and absent from the panel itself. Strawhacker challenged the audience to investigate why these meetings are not more relevant for, or accessible to, Indigenous communities. Returning to the starting premise that intersectionality provides a valuable frame for cultural examination, co-organizer Renuka Badhe, of the European Polar Board, noted during closing remarks at the event that there are many other minoritized groups who would benefit from an expanding dialogue about inclusivity in polar research. Organizations like IASC and SCAR should consider ways to better integrate inclusivity dialogues into their meeting programmes, encouraging all attendees to participate, and to develop and enforce codes of conduct for their own organizations.

If there was a unifying aspect of the "Taking the Helm" event, it was a shared aspiration to see a future for polar research that is ever more diverse, respectful and inclusive for all, one that supports a 
vibrant community of researchers through all career stages and enables them to rise to the height of their potential. Our collective efforts to better understand polar regions are impaired when we are not inclusive, and, at this critical time, we can't afford that. Let's work together to evolve a more positive work culture for all so that the adaptive strategies that women, people of colour and others have developed to cope with discrimination can become a thing of the past.

\section{Acknowledgements}

We would like to thank our sponsors for their support of the "Taking the Helm" event: Antarctic and Southern Ocean Coalition, Arctic Research Consortium of the USA, IASC, International Association of Cryospheric Sciences, International Glaciological Society, Ocean Expeditions, Ltd., Tinker Muse Prize, USA Arctic Research Commission and an Anonymous Private Donor. We would also like to thank our moderator, panellists and volunteer coordinator Meredith LaValley.

\section{Disclosure statement}

No potential conflict of interest was reported by the authors.

\section{ORCID}

Sandra Starkweather (D) http://orcid.org/0000-0001-73691891

\section{References}

Bell R.E. \& Koenig L.S. 2017. Harassment in science is real. Science 358, 1223.

Carey M., Jackson M., Antonello A. \& Rushing J. 2016. Glaciers, gender, and science: a feminist glaciology framework for global environmental change research. Progress in Human Geography 40, 770-793.

Clancy K., Nelson R., Rutherford J. \& Hinde K. 2014. Survey of Academic Field Experiences (SAFE): trainees report harassment and assault. PloS One 9, e102172, 10.1371/journal.pone.0102172.

Glasberg E. 2012. Antarctica as cultural critique: the gendered politics of scientific exploration and climate change. New York: Palgrave Macmillan.

Goulden M., Mason M.A. \& Frasch K. 2011. Keeping women in the science pipeline. Annals of the American Academy of Political and Social Science 638, 141-162.

Hulbe C., Wang W. \& Ommanney S. 2010. Women in glaciology, a historical perspective. Journal of Glaciology 56, 944-964.
Krupnik I., Allison R., Bell R., Cutler P., Hik D., LópezMartinez J., Rachold V., Sarukhanian E. \& Summerhayes C. (eds.) 2011. Understanding Earth's polar challenges: International Polar Year 2007-208, summary by the IPY Joint Committee. Rovaniemi, Finland: University of the Arctic.

McNutt M. 2017. Welcome in our field: attracting the best and brightest. Plenary session talk at 2017 Aquatic Sciences Meeting, Honolulu, HI.

NASEM (National Academies of Sciences, Engineering, and Medicine) 2018. Sexual harassment of women: climate, culture, and consequences in academic sciences, engineering, and medicine. Washington, DC: The National Academies Press.

Nash M., Lea M.-A., Shaw J., King M., Bax N. \& Nielsen H. 2018. Findings from a national survey on gender equity in Australian Antarctic Science. Poster presented at the Polar 2018 Open Science Conference, 15-26 June, Davos, Switzerland.

Nelson R., Rutherford J., Hinde K. \& Clancy K. 2017. Signaling safety: characterizing fieldwork experiences and their implications for career trajectories. American Anthropologist 119, 710-722.

Oreskes N. 1996. Objectivity or heroism? On the invisibility of women in science. Osiris 11, 87-113.

Rosner V. 2009. Gender and polar studies: mapping the terrain. Signs: Journal of Women in Culture and Society 34, 489-494.

Scoles S. 2018. The harassment problem in scientific dream jobs. Outside Online. Accessed online at https://www. outsideonline.com/2300656/harassment-problemscientific-dream-jobs?utm_content=bufferf $4 \mathrm{f} 3 \mathrm{~d} \& u$ tm medium $=$ social\&utm_source $=$ twitter\&utm_campaign $=$ tweet on 7 September 2018.

Seag M. 2017. Women need not apply: gendered institutional change in Antarctica and outer space. The Polar Journal 7, 319-335.

SRT (Subcommittee on Research and Technology; 115th Congress) 2018. Hearing-a review of sexual harassment and misconduct in science. Accessed online at https:// science.house.gov/legislation/hearings/subcommitteeresearch-and-technology-hearing-review-sexualharassment-and on 7 September 2018.

Starkweather S., Derry K. \& Crain R. 2017. Leveling the field: the role of preparation, leadership, and networks in empowering minoritized participants. Presented at the American Geophysical Union Fall Meeting, 11-15 December, New Orleans.

Waldman M. 2018. Boston University rejects geologist David Marchant's appeal of termination. Scientific Community, Science. Accessed online at http://www. sciencemag.org/news/2018/02/boston-university-rejectsgeologist-david-marchant-s-appeal-termination on 7 September 2018.

Willenbring J. 2018. The elephant in the women-in-science room. Speaking of Geoscience. Accessed online at https:// speakingofgeoscience.org/2018/06/29/the-elephant-in-the -women-in-science-room/ on 7 September 2018. 